\title{
A practical approach to HFI based Sensorless Control of PM-assisted Synchronous Reluctance Machines applied to EVs and HEVs
}

\author{
E. Trancho ${ }^{1}$, E. Ibarra ${ }^{2}$, A. Arias $^{3}$, I. Kortabarria ${ }^{2}$, P. Prieto ${ }^{1}$ \\ ${ }^{1}$ Tecnalia Research and Innovation, c/ Geldo, Edif. 700, 48160 Derio (Spain) \\ ${ }^{2}$ Department of Electronic Technology, UPV/EHU, C. Rafael Moreno Pitxitxi 3, 48013 Bilbao (Spain) \\ ${ }^{3}$ Institut d'Organització i Control, Universitat Politècnica de Catalunya, Diagonal, 647, 08028 Barcelona (Spain) \\ elena.trancho@tecnalia.com \\ 2017 IEEE Industrial Electronics Society IECON. Personal use of this material is permitted. \\ Permission from IEEE must be obtained for all other uses, \\ in any current or future media, including reprinting/republishing this material
}

for advertising or promotional purposes, creating new collective works, for resale or redistribution to servers or lists, or reuse of any copyrighted component of this work in other works.

DOI: $10.1109 /$ IECON.2017.8216294

\begin{abstract}
Sensorless control is a promising alternative for controlling Electric Vehicle (EV) and Hybrid Electric Vehicle (HEV) propulsion systems without the need of complex devices, such as resolvers or encoders. As the usage of a physical sensor is avoided, this allows significant cost reductions of the drive, and the reliability of the system is also improved. EVs require an operation range from standstill to high speeds. At low speeds, the back-EMF of the electric machine is low, and signal injection techniques are required in order to estimate the position and speed of the machine. This paper presents practical implementation details of the High Frequency Injection (HFI) technique, giving special attention to signal processing, offset compensation due to filtering delays and robust speed estimation. The approach is validated in an automotive Permanent Magnet Assisted Synchronous Reluctance Machine (PM-assisted SynRM) of $51 \mathrm{~kW}$.
\end{abstract}

\section{INTRODUCTION}

Synchronous machines are receiving a considerable attention for transport electrification, particularly for Electric Vehicle (EV) and Hybrid Electric Vehicle (HEV) propulsion systems [1]-[3]. Among the existing topologies, the ferrite Permanent Magnet Assisted SynRM (PM-assisted SynRM) electric machines are considered promising candidates for the next generation electrified vehicles [3], due to their low rotor losses, their high saliency ratio $\left(L_{q} / L_{d}\right)$ and the high torque and high power factor. Besides, rare-earth PMs (sintered neodymium-iron-boron $(\mathrm{NdFeB})$ alloy) are replaced by ferrite magnets, contributing to price reduction (ferrites are easy to produce and inexpensive materials) [3], [4].

Torque control strategies of these type of machines requires knowledge of the rotor position and speed. Commonly, resolvers and encoders are used in EV and HEV applications due to their ability to operate in harsh environments. The installation of such a sensor results in a greater cost, bigger size of the drive and reliability reduction, making sensorless control an attractive approach. The core of any sensorless control algorithm are the position and speed estimation algorithms, which perform the estimation from the measured phase currents and commanded voltages. Depending on the speed operation range, two estimation algorithm families can be distinguished [5], [6]:

- Observer based estimators. These techniques rely on the estimation of the back Electromotive Force (backEMF) to obtain the rotor position and speed. The backEMF force directly depends on the rotor speed, leading to estimation failures at low speeds or standstill [5], [7].

- Signal injection based techniques. This approach consists of injecting a high frequency excitation into the stator voltage terminals, producing specific frequency components in the currents that contain information about the rotor position, being commonly used for low speeds and standstill, where the back-EMF magnitude is low. In the case of Synchronous Machines, a certain degree of saliency is required in order to successfully apply this type of estimation techniques [5], [8]-[10]. Reviews of the signal injection techniques can be found in literature [11].

Thanks to their high saliency ratio, PM-assisted SynRM machines are addecuate for implementing signal injection sensorless techniques. However, as the back-EMF produced by the PMs is lower than in rare-earth based synchronous machines, the HFI must be extended up to higher operation speeds.

In this paper, practical implementation details of the High 
Frequency Injection (HFI) technique are presented, giving special attention to signal processing (filtering characteristics), offset compensation due to filtering delays and robust speed estimation designed to avoid noise produced glitches. The approach is validated in an automotive PM-assisted SynRM of $51 \mathrm{~kW}$.

\section{PM-ASSISTED SYNREL MODEL AND CONTROL FUNDAMENTALS}

The mathematical equations that model a PM-assisted SynRM in the $d q$ synchronous reference frame are the following:

$$
\begin{aligned}
& v_{d}=R_{s} i_{d}+\frac{d \Psi_{d}\left(i_{d}, i_{q}\right)}{d t}+\omega_{e} \Psi_{d}\left(i_{d}, i_{q}\right), \\
& v_{q}=R_{s} i_{q}+\frac{d \Psi_{q}\left(i_{d}, i_{q}\right)}{d t}-\omega_{e} \Psi_{q}\left(i_{d}, i_{q}\right),
\end{aligned}
$$

where $R_{s}$ is the stator resistance, $i_{d}$ and $i_{q}$ are the stator currents in the $d q$-axis reference frame, $\omega_{e}$ is the stator electrical speed and $\Psi_{d}\left(i_{d}, i_{q}\right)$ and $\Psi_{q}\left(i_{d}, i_{q}\right)$ are the current dependant magnetic fluxes including the magnetic saturation effect [12], [13], which are expressed as:

$$
\begin{gathered}
\Psi_{d}=L_{d}\left(i_{d}, i_{q}\right) i_{d}+\Psi_{P M}\left(i_{d}, i_{q}\right), \\
\Psi_{q}=L_{q}\left(i_{d}, i_{q}\right) i_{q},
\end{gathered}
$$

being $\Psi_{P M}$ the PM flux and $L_{d}$ and $L_{q}$ the $d$ - and $q$ axis inductances, respectively. The speed dependant terms of (1) and (2) represent the back-EMF in the $d$ - and $q$-axis, respectively. The electromagnetic torque can be obtained as follows:

$$
T_{e}=\frac{3}{2} P\left[\left(L_{d}-L_{q}\right) i_{d} i_{q}+\Psi_{P M} i_{q}\right],
$$

where $P$ is the pole-pair number.

From (5), it can be derived that a high value in $L_{d}-L_{q}$ leads to a high torque, being the power factor also affected by the $L_{q} / L_{d}$ ratio. Therefore, SynRMs are designed in a way that the highest value of $L_{q}$ and the lowest value is $L_{d}$ is achieved.

Regarding control aspects, torque regulation of PM-assisted SynRMs is very similar to the algorithms used for controlling rare earth PM based synchronous machines. In this sense, Field oriented Control (FOC) and Direct Torque Control (DTC) algorithms are the most commonly used [14]. However, due to the machine high saliency, the current regulators and field weakening strategies must be carefully designed and tuned. Figure 1 shows the general diagram of a HFI sensorless controlled PM-assisted SynRM, in which the position and speed estimation algorithm is a key element.

As this paper is focused in the HFI injection technique, the next section describes the fundamentals of this type of technique. For simplicity, no detail about the back-EMF observer will be given.

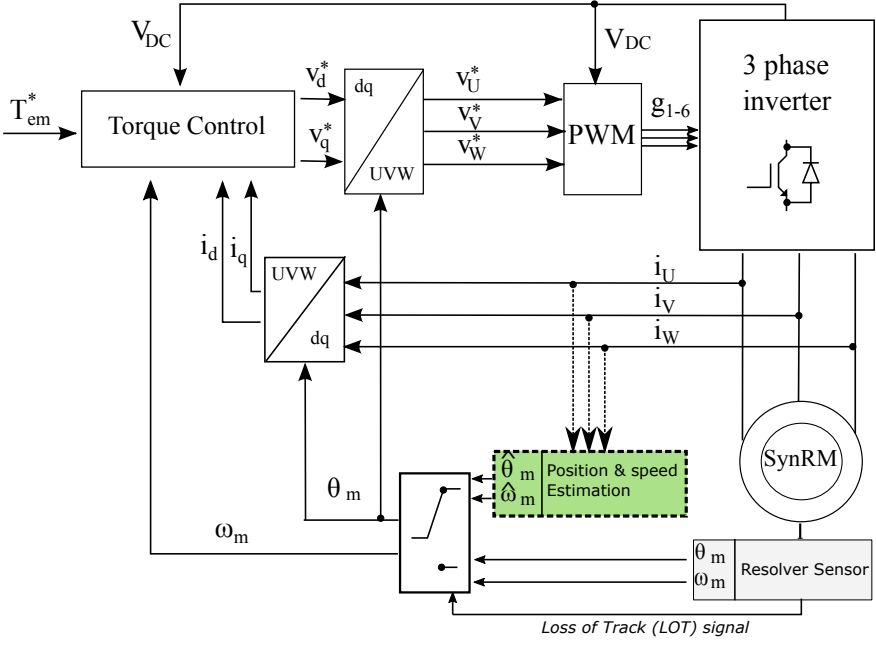

Fig. 1. General diagram of a PM-assisted SynRM torque control including a fault tolerant HFI sensorless strategy.

\section{HFI BASED SENSORLESS CONTROL FUNDAMENTALS}

\section{A. HFI sensorless strategy}

One of the most commonly used signal injection technique consists of injecting a rotating HF voltage vector as follows:

$$
\mathbf{v}_{i}=\left[\begin{array}{l}
v_{\alpha} \\
v_{\beta}
\end{array}\right]=V_{i}\left[\begin{array}{c}
-\sin \left(w_{i} t\right) \\
\cos \left(w_{i} t\right)
\end{array}\right],
$$

were $V_{i}$ is the amplitude of the introduced HF signal and $w_{i}$ is the high frequency rotation speed, being the rotation frequency $f_{i}=w_{i} / 2 \pi$ commonly of around $1 \mathrm{kHz}$.

Due to the saliency of the machine, the measured currents contain information of the rotor position at $w_{i}$ :

$$
\mathbf{i}_{i}=\left[\begin{array}{c}
i_{\alpha, i} \\
i_{\beta, i}
\end{array}\right]=\left[\begin{array}{l}
I_{0} \cos \left(\omega_{i} t\right)+I_{1} \cos \left(2 \theta_{e}-\omega_{i} t\right) \\
I_{0} \sin \left(\omega_{i} t\right)+I_{1} \sin \left(2 \theta_{e}-\omega_{i} t\right)
\end{array}\right],
$$

where $I_{0}$ and $I_{1}$ correspond to the positive and negative components of the HF stator currents. From (7), it is deduced that signal postproccesing is required to extract the information of the rotor position [5], [10]. The HFI diagram, including the currents processing, is provided in figure 2.

HFI based methods have some limitations that must be taken into account [9]:

- The usage of Band Pass Filters (BPF) and High Pass Filters (HPF) in the processing stage produce signal delays, which must be compensated. This delays can introduce significant offsets in the estimated angle, leading to an incorrect angle estimation that can reduce the drive efficiency (due to incorrect current vector application), produce deviations in the generated torque and complicate the transitions between the HFI and the observer based algorithms. This becomes more relevant in PMaSynRM machines, where HFI injection speed range must be extended. 


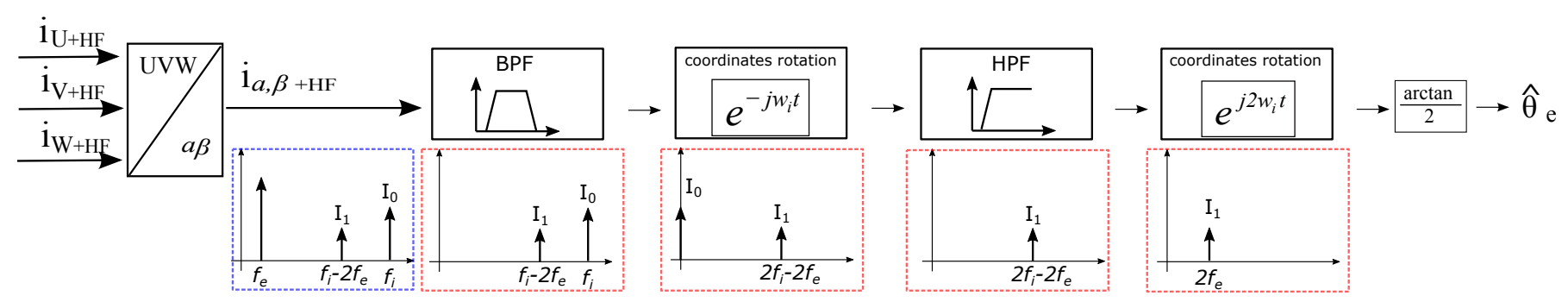

Fig. 2. HFI ssensorless strategy current processing.

- The HF injection produces additional perturbations to the system, causing additional torque ripple and increasing the losses.

- HFI detection signals do not distinguish the magnetic flux polarity.

\section{B. HFI polarity detection techniques at start-up}

When starting the drive, rotor position estimated throughout conventional HFI techniques does not distinguish between the north and south magnetic poles. If the initial estimated angle is aligned with the wrong pole, an offset of $\pi$ is added between the real and the estimated position and, as a consequence, the torque regulator produces the opposite torque. Obviously, this is unacceptable for the EV drive operation. Techniques for initial rotor position estimation are common in the scientific literature, and can be divided into two main groups:

- Carrier signal injection techniques exploit machine saliency to estimate the rotor position at start-up. Two approaches of carrier signals are commonly used [15], [16]: rotating (carrier signal is injected in the $\alpha \beta$ stationary reference frame) and pulsating (carrier signal is injected in the estimated $d q$ synchronous reference frame). In both cases, a rotating HF voltage signal is injected in the stator voltage terminals. Taking advantage of the machine saliency, information of the rotor position is obtained from the measured HF current components as follows [16], [17]:

$$
\begin{gathered}
i_{d q}^{s}=I_{p 1} e^{j\left(w_{i} t-\pi / 2\right)}+I_{n 1} e^{j\left(-w_{i} t+2 \theta_{r}+\phi_{1 n}\right)}+ \\
I_{p 2} e^{j\left(2 w_{i} t-\theta_{r}+\phi 2 p\right)}+I_{n 2} e^{j\left(-2 w_{i} t+3 \theta_{r}+\phi 2 n\right)},
\end{gathered}
$$

where $I_{p 1}, I_{p 2}, I_{n 1}$ and $I_{n 2}$ are the first and second order positive ( $p$ subindex) and negative ( $n$ subindex) sequence harmonic current components.

From (8), a post-processing stage is required to extract the initial rotor position $\left(\theta_{r}\right)$ information included at the second harmonic component $\left(2 w_{i} t\right)$ of the positive sequence $\left(I_{p 2}\right)$. Various signal processing solutions are proposed in the literature [16], [17]. The effectiveness of this method is achieved at the cost of introducing additional noise [15], which is a minor concern as the polarity detection techniques are only required at startup and during a short period of time.

- The pulse signal injection method operating principle consists on injecting short voltage stator pulses to obtain information of the magnetic pole position in order to correctly estimate the rotor angle at start-up states [18]. When applying voltage pulses of same amplitude and time duration, the magnitude peak of the stator current $i_{d}$ is measured. According to the saturation saliency principle [19], $d$-axis current magnitude is maximized as the voltage vector approaches the north pole. The robustness of the strategy decreases when noise interferes in the current sensors, as it cannot guarantee an exact pole orientation from small and noisy current variations. In [19], [20] voltage pulse magnitude is maximized to ensure enough current peak resolution. The pulse amplitude must be chosen in a way that drive standstill is guaranteed (too high voltage induces high currents which can consequently put into rotation the drive). As an alternative, an optimal voltage vector usage is proposed in [21].

Additionally, a third possibility to put the drive into operation from standstill can be considered, i.e., using an openloop strategy at start-up $(I / f$ or more widely known $V / f$ open loop strategies). These methods are characterized by their implementation simplicity at the cost of limited dynamic performance [18]. However, this alternative cannot be considered for the main EV propulsion system, as the torque production must be controlled from the beginning.

\section{HFI PRACTICAL IMPLEMENTATION}

\section{A. Filter design considerations}

Filter designing requires special attention when implementing a HFI based sensorless in a microprocessor, as the accuracy of the angle estimation directly depends of the filters correct adjustment. There are two important aspects to bear in mind when implementing a filter:

- Frequency specifications: Correct sample frequency $\left(f_{s}\right)$, passing frequency $\left(f_{\text {pass }}\right)$ and stop frequency $\left(f_{\text {stop }}\right)$ are needed to ensure a correct operation in the frequency bands.

- Filter order: As the order of the filters increases, the filters discriminate better unwanted frequencies. However, an order increase results in a significant increment of the computational burden that the micro-controller must handle. 


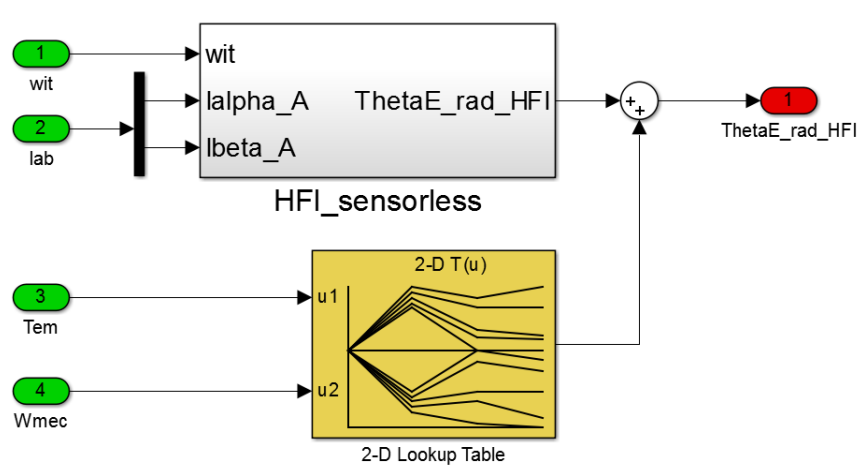

Fig. 3. HFI sensorless structure including angle deviation compensation strategy.

\section{B. Angle deviation compensation}

When implementing a HFI sensorless strategy in a real platform, the estimated rotor position may suffer deviations from the real value due to the usage of filters in the HF current processing stage.

Estimated position deviations lead to abrupt transitions from observer based to HFI sensorless and vice versa, causing control degradation or even control instability. Thus, it becomes clear the necessity of an angle deviation compensator to correctly implement a HFI sensorless. In this paper, an empirical Look-Up Table (LUT) based position error compensator is proposed. The compensator implementation is composed of the following stages:

1) Definition of the sensorless operation range in the torque vs speed curve:

$$
\begin{array}{r}
\omega_{m e c, i}=\left[-\omega_{\max }: \operatorname{step}_{\omega}: \omega_{\max }\right], \\
T_{e m, j}=\left[-T_{e m, \max }: \operatorname{step}_{T}: T_{e m, \max }\right],
\end{array}
$$

where $\omega_{m e c}$ is the mechanical speed, $T_{e m}$ is the electromagnetic torque, $s t e p_{\omega}$ and $s t e p_{T}$ are the interval between samples for speed and torque and the suffixes $i, j$ and $\max$ correspond to the speed samples, torque samples and maximum values, respectively.

2) Angle deviation parametrization. The machine is driven at the operation points defined in (9) and (10). In each point, the error between the real position $(\theta)$ and the estimated by the sensorless $(\hat{\theta})$ is obtained experimentally.

3) Integration of the angle deviation compensation in the sensorless control strategy. The resulting compensator is stored in a 2 dimensional Look-up Table (2D-LUT), as shown in figure 3 .

\section{Robust speed estimation from estimated angle}

Once the estimated position is obtained, the rotor speed is required by the controller feed-forward terms (figure 1). As the use of derivative calculations under noisy environments are common sources of error, a robust speed estimation method is proposed, as shown in the diagram of figure 4 .

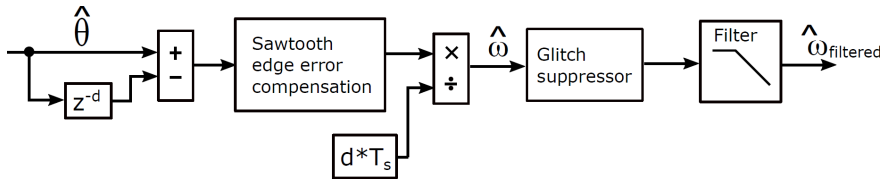

Fig. 4. Speed estimation process from estimated angle.

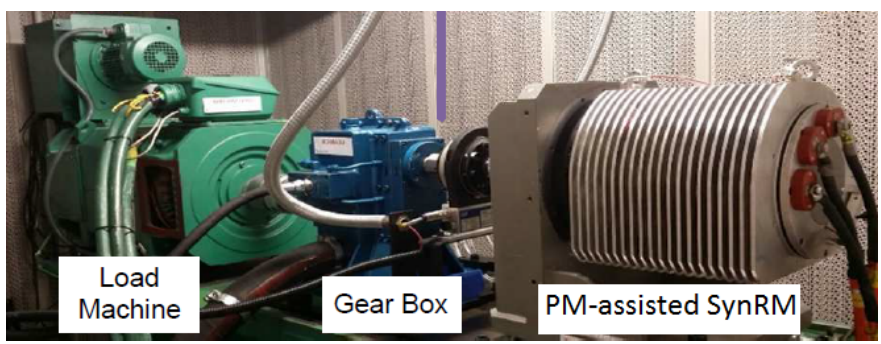

Fig. 5. Experimental platform including the load machine and the PMaSynRM machine.

In the proposed strategy, the position sawtooth gradient is obtained setting a delay $d$ between position signal samples. A sawtooth error compensator ("Sawtooth edge error compensation") is included to avoid errors produced by $2 \pi$-to0 transitions, or vice versa, which lead to incorrect speed estimation. Once the estimated speed $\hat{\omega}$ is obtained, a glitch suppressor strategy cancels evident undesired glitches that can occur due to noise. Finally, a low pass filter is added to reduce the possible remaining noise from the speed signal. The cutting frequency of this filter must be set according the acceleration dynamics of the drive.

\section{EXPERIMENTAL RESULTS}

\section{A. Experimental platform description}

The implemented hybrid sensorless strategy has been validated in an automotive PM-assisted SynRM drive of a maximum power of $51 \mathrm{~kW}$ and maximum speed of $12000 \mathrm{rpm}$. The test bench emulates the propulsion system throughout a 8000 rpm and $157 \mathrm{~kW}$ induction load machine (figure 5), and the maximum speed of the PM-assisted SynRM is achived thanks to a 1:1.8 gearbox. A dSPACE Rapid Control Prototyping (RCP) equipped with a DS1006 control board has been used to validate the algorithm, connected to a comercial Semikron IGD-1-424-P1N4-DL-FA inverter with a nominal power of $140 \mathrm{~kW}$ DC/AC. The switching frequency of the inverter has been set to $12.5 \mathrm{kHz}$.

The nominal parameters of the PM-assisted SynRM are shown in table I.

\section{B. Results}

The HFI sensorless strategy particularly developed for this application includes a HF voltage amplitude $V_{i}$ of $60 \mathrm{~V}$, at a rotating frequency $w_{i}$ of $1 \mathrm{kHz}$. The voltage amplitude has been set by trial and error, while the HF signal rotating frequency has been set as around 10 times greater than the switching frequency of the converter. The filters used for the HF current 


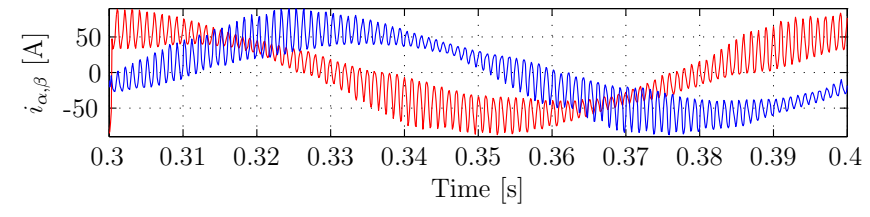

(a) $i_{\alpha \beta}$ measured including $\mathrm{HF}$.

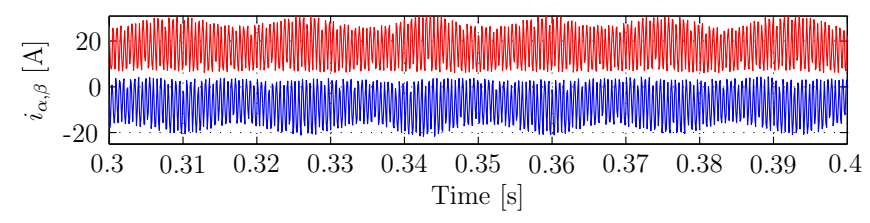

(c) Step 2: $i_{\alpha \beta}$ including coordinates rotation.

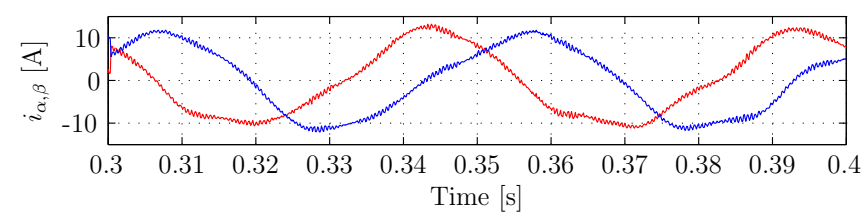

(e) Step 4: $i_{\alpha \beta}$ including coordinates rotation.

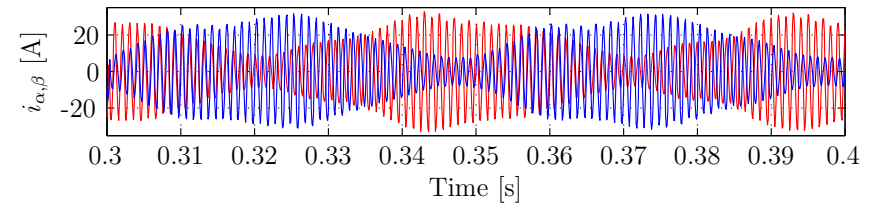

(b) Step 1: $i_{\alpha \beta}$ including Band Pass Filter.

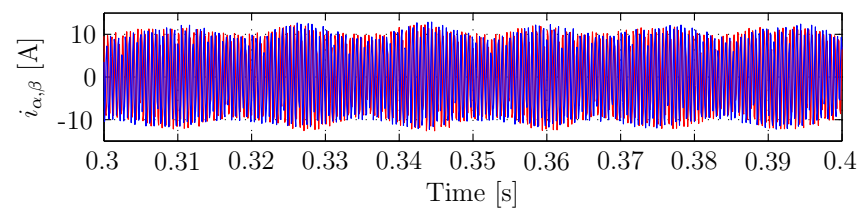

(d) Step 3: $i_{\alpha \beta}$ including High Pass Filter.

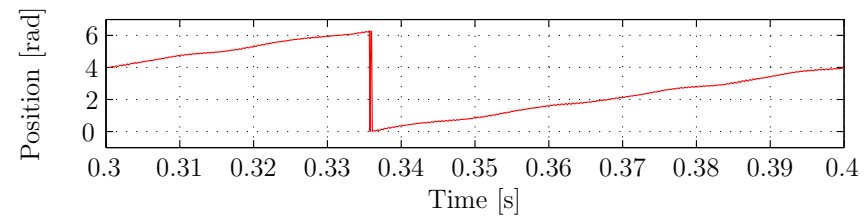

(f) Rotor position obtained

Fig. 7. Measured currents postprocesing process to obtain the rotor position.

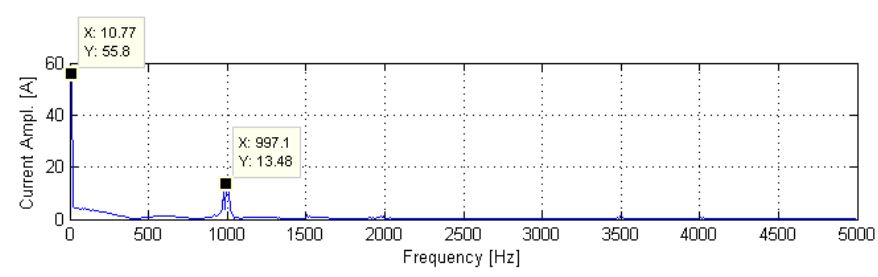

(a) $i_{\alpha}$ measured spectrum including HF.

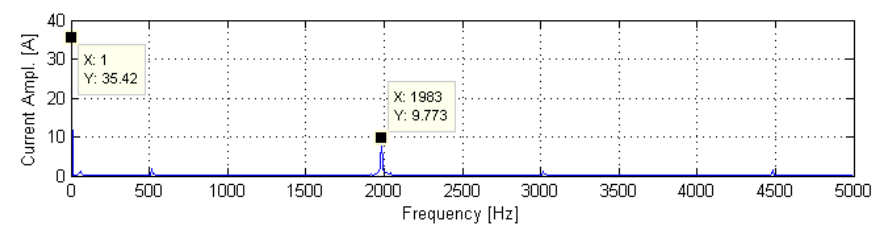

(c) Step 2: $i_{\alpha}$ spectrum after coordinates rotation.

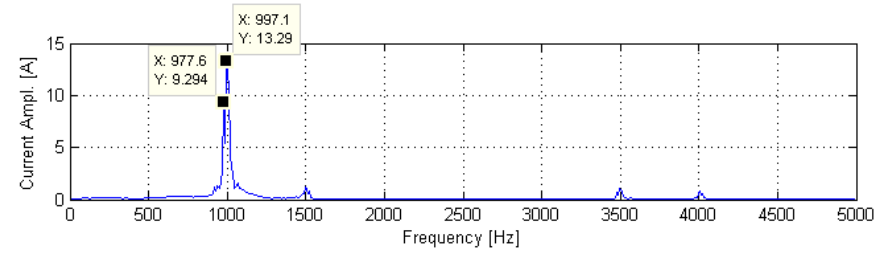

(b) Step 1: $i_{\alpha}$ spectrum after the Band Pass Filter.

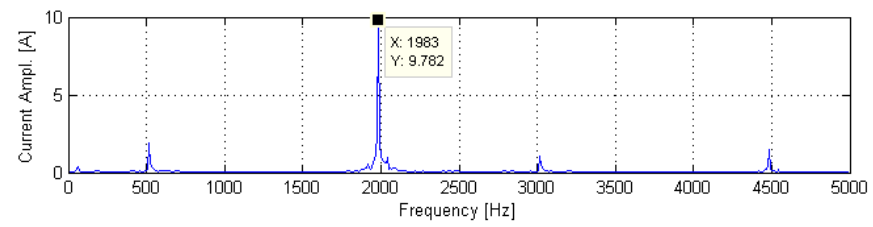

(d) Step 3: $i_{\alpha}$ spectrum after High Pass Filter.

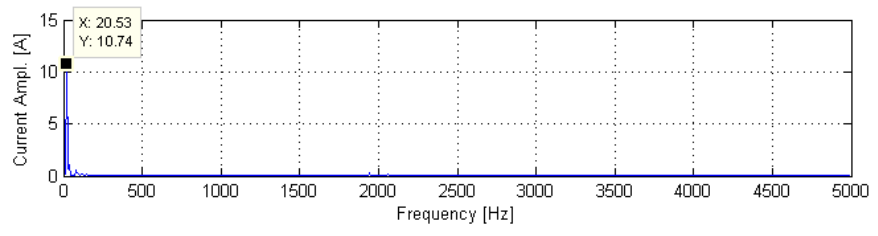

(e) Step 4: $i_{\alpha}$ spectrum after coordinates rotation.

Fig. 8. Current signal processing in the frequency domain.

processing stage have been obtained throughout the MATLAB fdatool toolbox. Concerning the angle compensator, the torque and speed arrays have been initialized as $T_{e m}=[0: 20: 100]$ and $\omega_{m e c}=[-1000: 200: 1000]$. For the speed estimation process, the distance between samples has been set to $d=50$, and the low pass filter is an IIR Butterword filter with a passing frequency $f_{\text {pass }}=10 \mathrm{~Hz}$ and $4^{\text {th }}$ order.
Figure 6 shows how correct position and speed estimations are obtained at standstill and at very low speeds using the HFI technique together with the angle deviation compensator and the robust speed estimator. Figure 7 shows the processed signals obtained to extract the rotor position information, i.e., the measured currents in the rotating reference frame $\left(i_{\alpha}, i_{\beta}\right)$ including the high frequency injection, the 4 steps that make 
TABLE I

MOST SIGNIFICANT PARAMETERS OF THE PM-ASSISTED SYNRM MACHINE.

\begin{tabular}{|c|c|c|c|}
\hline Item & Symbol & Value & Units \\
\hline Maximum power & $P_{N}$ & 51 & $\mathrm{~kW}$ \\
\hline Maximum speed & $w_{\max }$ & 12000 & $\mathrm{rpm}$ \\
\hline Machine Pole Pairs & $M_{P P}$ & 3 & - \\
\hline Stator Resistance & $R_{s}$ & 0.00174 & $\Omega$ \\
\hline d-axis nominal inductance & $L_{d}$ & $0.7 \mathrm{e}^{-} 3$ & $\mathrm{H}$ \\
\hline q-axis nominal inductance & $L_{q}$ & $1.7 \mathrm{e}^{-} 3$ & $\mathrm{H}$ \\
\hline Permanent Magnet Flux linkage & $\Psi_{P M}$ & 0.38 & $\mathrm{~Wb}$ \\
\hline
\end{tabular}

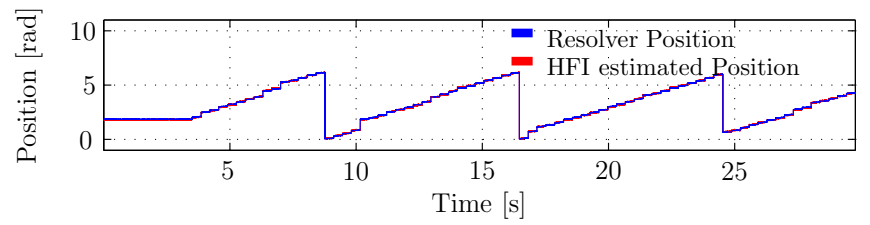

(a) Rotor position estimation.

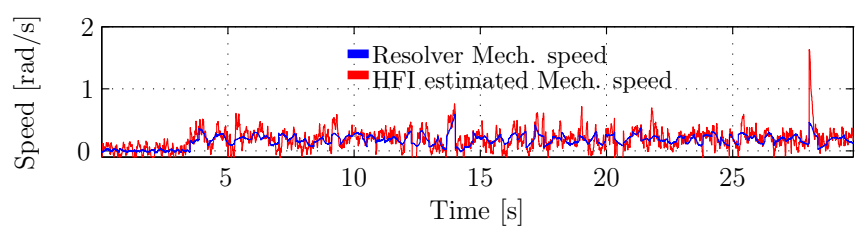

(b) Rotor speed estimation.

Fig. 6. Rotor position and speed estimation from standstill and low speeds using HFI sensorless.

up the post-processing task and the restored angle.

Finally, figure 8 analyses the current processing stage in the frequency domain. In figure 8(a), the PM-assisted SynRM is rotating at around $10.77 \mathrm{~Hz}$ and the $\mathrm{HF}$ signal is injected at $1000 \mathrm{~Hz}$. Once the fundamental frequency is removed throughout the BPF (figure 8(b)), the HF components lie on $1000 \mathrm{~Hz}$ and $(1000-2 \times 10.77) \mathrm{Hz}$, i.e. $978 \mathrm{~Hz}$. In figure 8(c), a rotation of coordinates moves the HF current at $1000 \mathrm{~Hz}$ to DC, while the position signal is moved $1000 \mathrm{~Hz}$ far away, lying on $(2000-2 \times 10.77) \mathrm{Hz}$, i.e. $1978 \mathrm{~Hz}$. The HPF used to remove the DC component produced by the previous rotation transformation is shown in figure 8(d). Finally, in figure 8(e), a back rotation to the synchronous frame is used to obtain the current component containing the position information at $2 \times 10.77 \mathrm{~Hz}$, i.e. $21.54 \mathrm{~Hz}$.

The slight deviations between the measured signal frequencies and the theoretical ones are caused by speed oscillations produced by the load machine speed control when operating at low speeds.

\section{Vi. Conclusions}

Sensorless control of EV and HEV drives requires the usage of a signal injection technique in order to perform position and speed estimations at low speeds and standstill. PM-assisted SynRM machines are great candidates for sensorless operation, due to the high saliency they exhibit.
In order to obtain a successful sensorless operation in a real scenario, this paper presents the most important practical aspects to be considered. In this sense, the initial angle detection algorithm, a proper processing stage design, an estimated angle offset compensator and a robust speed estimation under noisy environment must be taken into account to guarantee a correct HFI sensorless control implementation.

\section{ACKNOWLEDGMENTS}

This work has been supported by the Government of the Basque Country within the research program ELKARTEK as the project KT4TRANS (KK-2015/00047 and KK2016/00061), by the Ministerio de Economía y Competitividad of Spain within the project DPI2014-53685-C2-2-R and FEDER funds, by the Department of Education, Linguistic Policy and Culture of the Basque Government within the fund for research groups of the Basque university system IT978-16 and partially by the "Ministerio de Economía y Competitividad" from Spain under the ENE2012-36871-C0201 and DPI2013-41224-P Research Projects.

\section{REFERENCES}

[1] B. Asaei and B. Rahrovi, "Minimum-copper-loss control over full speed range of an ipmsm drive for hybrid electric vehicle application," in IEEE Vehicle Power and Propulsion Conference (VPPC), 2010.

[2] T. Finken, M. Hombitzer, and K. Hameyer, "Study and comparison of several permanent-magnet excited rotor types regarding their applicability in electric vehicles," in Emobility - Electrical Power Train Conference, 2010.

[3] J. Riba, C. Lomonova, E. Lopez, L. Romeral, and A. Garcia, "Rareearth-free propulsion motors for electric vehicles: A technology review,' Renewable and Sustainable Energy Reviews, no. 57, pp. 367-379, 2016.

[4] I. Boldea, L. Tutelea, L. Parsa, and D. Dorrell, "Automotive electric propulsion systems with reduced or no permanent mmagnet: An overview," IEEE Transactions on Industrial Electronics, vol. 61, no. 10, pp. 5696-5711, 2014

[5] A. Arias, G. Asher, M. Sumner, P. Wheeler, L. Empringham, and C. Silva, "High frequency voltage injection for the sensorless control of permanent magnet synchronous motors using matrix converters," in Proc. of the IEEE Industrial Electronics Conference (IECON), 2004.

[6] R. P. F. Parasiliti and M. Tursini, "Sensorless speed control of a pm synchronous motor based on sliding mode observer and extended kalman filter," IEEE, 2001.

[7] A. Piipo, M. Hinkkanen, and J. Luomi, "Sensorless control of pmsm drives using a combination of voltage model and hf signal injection," in Proc. of the IEEE Industry Applications Conference, 2004.

[8] Y. Inoue, S. Morimoto, and M. Sanada, "A novel control scheme for maximum power operation of synchronous reluctance motors including maximum torque per flux control," IEEE Transactions on Industry Applications, vol. 47, no. 1, pp. 115-121, 2011.

[9] C. Silva, G. Asher, and M. Summer, "Hybrid rotor position observer for wide speed-range sensorless pm motor drives including zero speed," IEEE Transactions on Industrial Electronics, 2006.

[10] I. Omrane, W. Dib, E. Etien, and O. Bachelier, "Sensorless control of pmsm based on a nonlinear observer and a high-frequency signal inj ection for automotive applications," IEEE, pp. 3130-3135, 2013.

[11] C. Staines, C. Caruana, and R. Raute, "A review of saliency-based sensorless control methods for alterning current machines," IEEJ Journal of Industry Applications, vol. 3, no. 2, p. 8696, 2013.

[12] J. Cintron-Rivera, S. Foster, C. Nino-Baron, and S. E.G., "High performance controllers for interior permanent magnet synchronous machines using look-up tables and curve-fitting methods," in IEEE International Electric Machines \& Drives Conference (IEMDC), 2013, pp. 268-275.

[13] W. Peters, O. Wallsccheid, and J. Bockere, "A precise open-loop torque control for an interior permanent magnet synchronous motor (ipmsm) considering iron losses," in Annual Conference of the IEEE Industrial Electronics Society (IECON), 2012, pp. 2877-2882. 
[14] X. Garcia, B. Zigmund, A. Terlizzi, T. Pavlanin, and L. Salvatore, "Comparison between foc and dtc strategies for permanent magnet synchronous motors," Advances in Electrical and Electronic Engineering, pp. 76-81, 2004.

[15] J. Holtz, "Initial rotor polarity detection and sensorless control of pm synchronous machines, 2006," Industry Applications Conference, 41stIAS Annual Meeting IEEE, 2006.

[16] H. Kim, K. Huh, and R. Lorenz, "A novel method for initial rotor position estimation for ipm synchronous machine drives," IEEE Transactions in Industrial Electronics, vol. 40, no. 5, p. 13691378, 2004.

[17] J. Ha, I. K., T. Sawa, and S. Sul, "Sensorless position control and initial position estimation of an interior permanent magnet motor," Industry Applications Conference, 2001. 36th IAS Annual Meeting IEEE, p. 761767, 2001

[18] N. Chen, Z. Wang, S. Yu, W. Gui, and Y. Guo, "A new starting method of sensorless pmsm motors based on stm32f103b," Control Conference (CCC), 2010.

[19] X. Wu, H. Wang, S. Huang, K. Huang, and L. Wang, "Sensorless speed control with initial position estimation for surface mounted synchronous motor drive in electric vehicles," Energies, p. 1103011 046, 2015.

[20] Y. Yan, J. Zhu, and Y. Guo, "Initial rotor position estimation and sensorless direct torque control of surface mounted permanent magnet synchronous motors considering saturation saliency," IET Electric Power Applications, vol. 2, no. 1, p. 4248, 2008.

[21] K. Tanaka, T. Yuzawa, R. Morimyama, and I. Miki, "Initial rotor position estimation for surface permanent magnet synchronous motor," Industry, p. 25922597,2001 